\title{
Continuous training in school and the manager's role in the construction of critical collaboration spaces
}

\section{A formação contínua na escola e o papel do gestor na construção de espaços de colaboração crítica}

\section{Formación continua en la escuela y el papel del gerente en la construcción de espacios de colaboración críticos}

\author{
Sandra Santella de Sousa ${ }^{1}$ iD Fernanda Coelho Liberali $^{1}$ iD, Cristina Rosa David Pereira da Silva1 ${ }^{1 D}$ \\ ${ }^{1}$ Pontifícia Universidade Católica de São Paulo, São Paulo, São Paulo, Brasil.
}

Autor correspondente:

Sandra Santella de Sousa

Email: ssantella@hotmail.com

Como citar: Santella Sousa, S., Liberali, F. C., \& David Silva, C. R. P. (2021). Continuous training in school and the manager's role in the construction of critical collaboration spaces. Revista Tempos e Espaços em Educação, 14(33), e14204. http://dx.doi.org/10.20952/revtee.v14i33.14204

\begin{abstract}
This article addresses the importance of continuing education for teachers and pedagogical coordinators, taking as a reference the critical-collaborative proposal, through the experiences lived by researchers in the private and municipal networks of São Paulo and the research report of the Professional Master's Degree in Education. Our objective is to understand the importance of the role of the manager-educator in the continuing education of teachers and pedagogical coordinators. The studies are based on the central concepts of the Socio-Historical-Cultural Activity Theory and continuing education from a critical-collaborative perspective. The actions of the researchers were carried out through the methodology of Critical Collaborative Research, considering the intentional transformation of contexts and participants. Data collection and production took place through participant observation of the researchers during the educational process. The results point to the importance of promoting the critical-collaborative process in a privileged space in continuing education to articulate actions to transform practice.
\end{abstract}

Keywords: Continuous education. Critical collaboration. School management.

\section{RESUMO}

Este artigo aborda a importância da formação contínua de professores e coordenadores pedagógicos, tomando como referencial a proposta crítico- colaborativa, por meio das experiências vivenciadas por pesquisadoras nas redes privada e municipal de São Paulo e do relato de pesquisa do Mestrado Profissional em Educação. Tomamos como objetivo compreender a importância do papel do gestor-formador na formação contínua de professores e coordenadores pedagógicos. Os 
estudos estão baseados nos conceitos centrais da Teoria da Atividade Sócio-Histórico-Cultural e da formação contínua sob a perspectiva crítico-colaborativa. As ações das pesquisadoras foram realizadas por meio da metodologia da Pesquisa Crítica de Colaboração, pensando a transformação intencional de contextos e dos participantes. A coleta e a produção de dados ocorreram por meio da observação participante das pesquisadoras durante o processo formativo. Os resultados apontam para a importância da promoção do processo crítico-colaborativo em espaço privilegiado na formação contínua para articular ações de transformação da prática.

Palavras-chave: Colaboração crítica. Formação contínua. Gestão escolar.

\section{RESUMEN}

Este artículo aborda la importancia de la formación continua para docentes y coordinadores pedagógicos, tomando como referencia la propuesta crítico-colaborativa, a través de las experiencias vividas por las investigadoras en las redes privadas y municipales de São Paulo y el informe de investigación de la Maestría Profesional en Educación. Nuestro objetivo es comprender la importancia del rol de gestor-formador en la formación continua de docentes y coordinadores pedagógicos. Los estudios se basan en los conceptos centrales de la teoría de la actividad sociohistórica-cultural y la formación continua desde una perspectiva crítico-colaborativa. Las acciones de las investigadoras se llevaron a cabo a través de la metodología de la Investigación de Colaboración Crítica, considerando la transformación intencional de contextos y participantes. La recolección y producción de datos se realizó a través de la observación de la participación de las investigadoras durante el proceso de capacitación. Los resultados apuntan a la importancia de promover el proceso crítico-colaborativo en un espacio privilegiado en la formación continua para articular acciones de transformación de la práctica.

Palabras clave: Colaboración crítica. Formación continua. Gestión escolar.

\section{INTRODUÇÃO}

Atualmente, a formação de professores tem sido amplamente debatida em diversas esferas, seja acadêmica, profissional ou pessoal. A formação contínua pode ser vista como um processo permanente e necessário à atuação docente realizada ao longo de toda vida profissional (Almeida \& Placco, 2009).

A profissão docente exige demandas que já não são mais atendidas pela educação tradicional, aquela concebida pela transmissão de conhecimentos, "a motivação, luta contra a exclusão social, participação, animação de grupos, relações com estruturas sociais, com a comunidade" (Imbernón, 2011, p. 14). Assim, a atuação docente necessita ir além da formação inicial para atender as demandas sociais atuais que perpassam pela educação, é necessário formação contínua.

O presente artigo aborda os estudos realizados no âmbito acadêmico e a análise de experiências voltadas para a formação contínua, desenvolvida pelas autoras-pesquisadoras em suas unidades de trabalho em São Paulo. As experiências formativas e de pesquisa proporcionaram às pesquisadoras subsídios teórico-metodológicos para o desenvolvimento de ações educacionais de formação contínua sob a perspectiva da colaboração crítica-reflexiva e que resultaram em redimensionamento de suas práticas pedagógicas.

Tal objeto de estudo foi observado por meio da ancoragem teórica da Teoria da Atividade Sócio-Histórico-Cultural (TASHC) de Vygotysky e de seus seguidores, que consideram a capacidade dos sujeitos de agirem intencionalmente e a transformarem suas realidades.

Tomamos como objetivo compreender a importância do papel do gestor-formador na formação contínua de professores e coordenadores pedagógicos. Para alcançar os objetivos de pesquisa, utilizamos como aporte metodológico a Pesquisa Crítica de Colaboração (PCCol) (Liberali \& Magalhães, 2004). 
Assim, apresentaremos os dados e discussão dos resultados alcançados das pesquisas de Mestrado Profissional desenvolvidas no programa de Pós-Graduação em Educação: Formação de formadores (FORMEP) da Pontifícia Universidade Católica de São Paulo (Santella Sousa, 2019; David Silva, 2019), oferecendo um panorama dos contextos em que estão inseridos, a fim de discutir criticamente a formação contínua de professores e coordenadores pedagógicos, ao propor apontamentos na perspectiva crítico colaborativa.

\title{
DESENVOLVIMENTO: A FORMAÇÃO CONTÍNUA NO CONTEXTO DA COLABORAÇÃO CRÍTICA
}

O presente artigo traz o relato de pesquisas desenvolvidas no contexto do Grupo de Pesquisa Linguagem em Atividades em Contextos Escolares (LACE) ${ }^{1}$, em que idealizamos a pesquisa em processos de colaboração e na ação conjunta dos agentes envolvidos - pesquisadores e participantes. Os referenciais teóricos utilizados neste trabalho são fundamentados na Teoria da Atividade Sócio-Histórico-Cultural.

A partir dessa base teórica, discute-se o papel da gestão escolar (coordenador e diretor), além de buscar as referências da formação contínua e sua importância no desenvolvimento profissional baseados em estudos de Imbernón (2011) e Nóvoa (1995) para a formação contínua de professores. Desse modo, a formação contínua dos professores e coordenadores pedagógicos, consideradas neste artigo, é a formação construída no cotidiano escolar, nas reuniões realizadas no horário cotidiano diário, definidos como os tempos que o professor tem disponível para seus estudos, atividades de formação contínua na escola, com a gestão do coordenador pedagógico.

O fio condutor das discussões sobre a formação contínua de professores está no processo crítico-colaborativo com foco na criação de situações de transformação a partir das necessidades reais e com a participação de todos os envolvidos. A concepção de formação de professores, abordada neste trabalho, está apoiada no conceito de desenvolvimento profissional (Imbernón, 2011), considerando que, dentre tantos fatores que promovem o desenvolvimento profissional docente, a formação contínua está imbricada nele. A formação contínua faz parte do crescimento profissional que acontece ao longo da atuação docente, podendo proporcionar um novo sentido à prática pedagógica, e ressignificando a atuação do professor.

Nesse sentido, Imbernón (2011, p.72) defende que a formação docente é elemento importante para o desenvolvimento profissional:

\begin{abstract}
Avaliar a necessidade potencial e a qualidade da inovação educativa que deve ser introduzida constantemente nas instituições; desenvolver habilidades básicas no âmbito das estratégias de ensino em um contexto determinado, do planejamento, diagnóstico e da avaliação; proporcionar as competências para ser capazes de modificar as tarefas educativas continuamente, em uma tentativa de adaptação à diversidade e ao contexto dos alunos; comprometer-se com o meio social. Tudo isso supõe uma formação permanente que desenvolva processos de pesquisa colaborativa para o desenvolvimento da organização, das pessoas e da comunidade educativa.
\end{abstract}

A formação colaborativa está na ação conjunta dos agentes envolvidos, em um espaço que propicie a participação, sendo essencial que cada um possa acreditar que suas contribuições serão consideradas. Desse modo, a formação colaborativa necessita da criação de espaços de participação, sendo fundamental a atuação da gestão escolar nesse processo.

\footnotetext{
${ }^{1}$ Grupo de Pesquisa Linguagem em Atividades em Contextos Escolares (LACE). Este grupo, credenciado pela PUC-SP e pelo CNPq em 2004, tem como foco principal a formação de alunos e educadores crítico-reflexivos. Integra duas temáticas centrais: Linguagem, Colaboração e Criticidade, sob a liderança da Profa. Dra. Maria Cecília Magalhães; e Linguagem Criatividade e Multiplicidade, sob a liderança da Profa. Dra. Fernanda Liberali.
} 
Trazer novas questões da prática e buscar compreendê-las sob o enfoque da teoria e articular novos saberes na construção da docência ampliam o diálogo com os envolvidos no processo que envolve a formação (Imbernón, 2011). O autor considera que a formação contínua integra o conceito de desenvolvimento profissional, mas não é seu único fator. Para ele (Imbernón, 2011), fatores como a formação inicial, condições de trabalho, clima escolar, questões sociais, lutas sindicais também integram situações que implicarão no desenvolvimento docente, ou não.

Assim, consideramos que os processos formativos são complexos, não tem início ou fim na formação, mas passam por um processo de desenvolvimento que está presente em toda vida. Imbernón (2011) ressalta a formação contínua como incentivo de desenvolvimento pessoal, profissional dos professores, aprimorando seu trabalho para transformação de uma prática.

A fim de avançarmos a discussão sobre a formação de professores, buscamos ampliar a compreensão da formação contínua no contexto da colaboração crítica, objeto de nossos estudos. Fullan \& Hargreaves (2001, p. 41) consideram que a formação contínua está condenada ao fracasso quando assume a forma de que "é feita aos professores e não com eles, muito menos por eles". Segundo os autores, é preciso renovar e investir na cultura da cooperação, no comprometimento e responsabilidade partilhados, em que as pessoas possam ser enriquecidas pelas atividades em grupo.

Fullan \& Hargreaves (2000) consideram que a colaboração que acontece de forma limitada e com pouca profundidade, somente como uma troca de atividade e/ou de dicas, oferecimento de conselho, e com foco em uma ação imediata, não abarca os valores necessários ao desenvolvimento crítico. Assim, os autores definem como colaboração confortável aquela que não reflete a prática e que não faz romper com os paradigmas da transmissão do saber, ou seja, a educação tradicional. Para a construção de uma cultura colaborativa com foco e com profundidade, é preciso priorizar o planejamento conjunto, dentro de um tempo que seja necessário para sua constituição. Nessa instância, a participação da gestão escolar é fundamental para a consolidação desse processo.

Desse modo, trabalhar coletivamente não significa que todos estarão agindo da mesma forma, pensando igualmente ou falando em uníssono. Segundo Liberali (2015, p. 79), na formação crítica e colaborativa, os sujeitos "preocupam-se em alcançar um ponto em comum com os demais na tentativa de encontrar uma possibilidade de combinação de vozes distintas na busca de um significado compartilhado".

O trabalho crítico-colaborativo, construído coletivamente, perpassa pelo confronto de ideias, pela negociação a fim de atingir um objetivo que seja comum a todos. Ou seja, as escolhas feitas por um sujeito diante das ideias apresentadas em um grupo seguirão os recursos para sustentar suas afirmações na produção de conhecimentos científico e cotidiano, na refutação e na busca por acordo provocando transformação nos sujeitos.

Colaborar, em qualquer contexto (pesquisa, formação contínua, sala de aula), significa agir no sentido de possibilitar que os agentes participantes tornem seus processos mentais claros, expliquem, demonstrem, com o objetivo de criar, para os outros participantes, possibilidades de questionar, expandir, recolocar o que foi posto em negociação. Implica, assim, conflitos e questionamentos que propiciem oportunidades de estranhamento e de compreensão crítica aos integrantes. (Liberali et al., 2006, p. 181).

A construção da colaboração crítica na formação não pode estar baseada na passividade dos participantes, mas sim, com foco para a produção de relações dialéticas e na discussão colaborativa das questões da prática, da realidade e do cotidiano da unidade escolar.

Desse modo, para que os professores assumam uma postura crítica colaborativa diante de sua formação e de sua prática pedagógica, é preciso refletir criticamente suas ações, entenderemse sujeitos intelectuais e produtores de conhecimento, capazes de transformar a ação, transformando sua prática e sua realidade. 
Ao apresentar a formação de professores na perspectiva de reflexão sobre a prática e reconstrução social, Liberali (2004; 2009; 2015), com base na teoria de Smyth (1992), envolvem as seguintes etapas: sugere algumas etapas reflexivas: descrever, informar, confrontar e reconstruir. A autora propõe que as etapas reflexivas permitem que a realidade seja transformada por processos que requerem novas estruturas de distribuição de poder. Desse, os processos de transformação que conduzem a confrontos polêmicos dentro de uma realidade diversa em que o desfecho, ainda que imprevisível, será a instauração da mudança.

Portanto, as etapas reflexivas, envolvem as seguintes etapas:

- Descrever: ao descrever a ação, o professor tem a possibilidade de rever sua prática, auxiliando sua percepção sobre a prática.

- Informar: essa etapa está organizada a partir de conceitos teóricos e pode revelar as concepções e princípios do professor. Realizando um processo de emersão das práticas é necessário que o educador retome alguns conceitos e teorias fundamentais sobre as questões de sala de aula.

- Confrontar: e ato de confrontar exige um questionamento profundo dos valores que estão na base das ações pedagógicas do docente e das bases teóricas. Nesse processo o professor diante dos dilemas pode aceitar, negociar ou ainda refutar o que está sendo debatido, construído.

- Reconstruir: o processo de reconstruir está ligado a transformação, ou seja, quando o educador percebe que suas práticas não são imutáveis e que pode planejar mudanças.

Todo processo de mudança, segundo Fullan \& Hargreaves (2001), estão conduzidos por confrontos polêmicos, sejam internos ou ligados a uma realidade diversa, os participantes da formação devem estar envolvidos no movimento de escuta, de participação ativa, mostrar-se preparados para mudança, dar a oportunidade de confrontar suas ideias, estar preparado para a tomada de decisão criando uma comunidade que seja capaz de desenvolver interesses comuns para a realidade da unidade escolar.

\title{
PROCEDIMENTOS TEÓRICO-METODOLÓGICOS
}

Utilizamos, como aporte metodológico, a perspectiva da Pesquisa Crítico Colaborativa (PCCol) (Liberali \& Magalhães, 2004), que propõe um espaço para discussão crítica da formação de professores, na medida em que aponta para a mudança intencional da realidade, a partir das necessidades reais, em um espaço de colaboração.

Assim, para as autoras:

\begin{abstract}
A Pesquisa Crítica de Colaboração (PCCol) é uma proposta de organização teórico-metodológica na construção de projetos de pesquisa de intervenção social em contextos escolares. Propõe a criação de contextos em que os participantes possam intervir no mundo real e produzir condições sociais mais justas e igualitárias. (Liberali \& Magalhães, 2017 p. 161).
\end{abstract}

A ancoragem metodológica na PCCol possibilitou espaços colaborativos, onde todos são ouvidos, pensando a criação de contextos de transformação ativa. A colaboração envolve a ideia de participação dos sujeitos de pesquisa e do pesquisador, por meio do compartilhamento e desenvolvimento coletivo.

Para coleta, produção e análise de dados, participamos dos momentos formativos que serão relatados. As categorias reflexivas - descrever, informar, confrontar e reconstruir - utilizadas no campo de análise, nos auxiliaram a indagar sobre os princípios que embasam a ação do professor (Liberali, 2015; Smyth, 1992), como segue:

- Descrever: relato detalhado do encontro formativo; 
- Informar: explicação das ações fundamentadas em base teórica;

- Confrontar: avaliação das ações dos sujeitos em relação a abordagem teórica levantada sobre a formação contínua de professores e

- Reconstruir: proposição de ações concretas futuras.

A seguir descreveremos o contexto formativo das duas unidades participantes, para então, na discussão, seguir os passos metodológicos de informar, confrontar e reconstruir.

\section{CONTEXTO FORMATIVO 1: RELATO DA FORMAÇÃO DOCENTE NA REDE PARTICULAR}

O contexto da pesquisa no âmbito escolar privado é um Grupo Educacional particular da cidade de São Paulo, mantenedor de quatro unidades escolares, que oferece serviços educacionais a bebês e crianças de quatro meses até dez anos. Para este artigo, utilizamos como sujeitos de estudo a formação com foco nas coordenadoras pedagógicas (CP).

A pesquisadora, gestora da unidade particular, atua na direção pedagógica e supervisiona a parte pedagógica de todas as mantidas, e por isso a preocupação e necessidade de trabalhar a formação das CPs. Portanto, entender o papel da diretora-pesquisadora sobre o processo formativo das coordenadoras iniciantes torna-se essencial para os caminhos desejados. Segue breve descrição dos encontros e temas abordados com o cronograma das tarefas e datas:

Primeiro Encontro (15/02/2019) - Reunião com as coordenadoras para explicação sobre a pesquisa e objetivos. Nesse encontro foi realizada apresentação da pesquisa e dos termos de consentimento para participação, além da leitura de texto e de discussão.

A proposta da formação consistiu em debater as relações entre coordenação pedagógica e toda a rotina que abarca a função. A pesquisadora justificou que iria fazer um levantamento de expectativas das coordenadoras para planejar os próximos momentos da formação. No encontro, foi realizada leitura de um trecho retirado do livro da professora Laurinda Ramalho de Almeida - 0 Coordenador Pedagógico e Questões da Contemporaneidade, escolhido para reflexão (Almeida \& Placco, 2012).

Após a leitura, foi solicitado que todas as participantes relatassem suas impressões acerca do que foi lido e se tinham uma proposta de intervenção sugerida para esse texto. As participantes se manifestaram e, durante o encontro, com pequenas intervenções, realizaram registros dos pontos principais levantados pelas coordenadoras, assim como as observações da pesquisadora.

Segundo Encontro (08/04/2019) - tema "Ensine as crianças a pensar, não o que pensar" composta pelo curta metragem La Luna e texto reflexivo. Nesse encontro, o exercício de reflexão crítica de informar, confrontar e reconstruir o conteúdo foi realizado como proposta de atividade. As CPs participaram de todos os processos: assistir ao vídeo, fazer a leitura do texto e a reflexão sobre as colocações da formadora.

Para finalizar, realizaram-se uma discussão sobre o vídeo e a leitura sobre como se deu a construção e a utilização desse recurso e seus benefícios para a execução do trabalho do grupo, como processo de reflexão sobre as contribuições para a prática. Como mediadora do encontro, a diretora-pesquisadora questionou o grupo sobre a aprendizagem, o trabalho em equipe e a metodologia educacional aliando à aprendizagem por meio do filme curta metragem. Durante a discussão foi observado que foi possível transpor as questões do curta metragem para questões do âmbito do exercício da coordenação pedagógica, sobre a interação entre professor, professor aluno, professor coordenador e equipe gestora.

Terceiro Encontro (02/05/2019) - questões foram colocadas ao grupo para iniciar a reflexão sobre os encontros formativos. Que ações de estudar desenvolve/buscam para sua própria formação atualmente? Qual ou quais temáticas de formação para o CP do Berçário, da Educação Infantil e do Ensino Fundamental nos anos iniciais considera importante para o desenvolvimento de suas funções? Você se enxerga como uma formadora? Dentro da sua rotina, consegue incluir a 
formação aos docentes? Como acredita poder incluir e de que forma? Descreva quais são os seus sucessos enquanto CP nesta unidade. Acredita que a formação contínua é importante para o seu desenvolvimento? Segue excerto da discussão:

CP I: É muito rica a entrevista de professores que têm capacitações e frequentam simpósios. Com a minha pós em Psico abriu meu olhar para a Educação Infantil, contribuiu para continuar estudando porque eu descobri que nada sei e consegui entender e passar para os pais mais ansiosos que a Educação Infantil prepara a criança para o Fundamental e não tem a função alfabetizadora que tantos pais buscam desde o berçário... (vergonhosamente eu também tinha essa ideia).

CP E: O tempo que eu trabalho em sala de aula com as professoras, o tempo que pesquiso para ensiná-las contribui muito para o meu desenvolvimento como CP.

CP L: A capacitação da minha equipe, nossos encontros (reuniões semanais) faz com que eu pesquise e tente solucionar (sanar) suas dúvidas e dificuldades dentro do ambiente escolar.

Muitas das vezes, o professor não consegue solucionar um problema de sala de aula, incluir um aluno (autista) para realizar as tarefas;

Um professor sem rotina, que não tem uma organização;

Professor que ao menos se dedicou em estudar o planejamento da sua turma e acredita que devemos ter apenas o assistencialismo com os alunos e não desenvolve aspectos pedagógicos.

A seguir faremos um breve relato da formação no contexto da escola pública, para então avançar na discussão dos resultados.

\section{CONTEXTO FORMATIVO 2: FORMAÇÃO CONTÍNUA NA REDE PÚBLICA MUNICIPAL}

A formação "Blog e as mídias sociais na escola", promovido pelo Núcleo de Educomunicação ocorreu em uma unidade de Educação Fundamental da Prefeitura de São Paulo. A escola localizada na região noroeste da capital paulista, periferia da cidade, atende alunos do Ensino Fundamental I e II. O curso ocorreu entre 04 de setembro e 09 de outubro de 2018, totalizando seis encontros de três horas. Dos 35 inscritos no curso, 21 professores frequentaram a formação. Dentre os integrantes, 15 eram da escola participante e os outros 6 de outras unidades escolares da região. Desse modo, 7 escolas participavam da formação representadas por seus docentes. Segue breve descrição dos encontros formativos.

No Primeiro encontro os docentes se apresentaram contando sua trajetória profissional e acadêmica, e, ao apresentar o curso, comentou que iria fazer um levantamento de expectativas para planejar o curso, explicando. A performance que foi solicitada ao grupo, de expor suas experiências e expectativas, nos grupos de trabalho e, depois, na apresentação geral para o grupão, demostrou abertura para o diálogo com problematização do que foi apresentado e reflexão sobre novas formas de pensar.

Ao final da apresentação dos slides, foi dado início à confecção do blog com a intenção de utilizar o blog como ferramenta prática durante o curso. Dos participantes, cinco professores contaram que são bloggers e utilizam o blog como ferramenta de registro de suas atividades; dois professores que atuam como Professores Orientadores de Informática Educativa (POIE) contaram que usam o blog como recurso para pesquisas em suas aulas, os demais professores se declararam apenas leitores de blog, nunca o tinham utilizado como ferramenta pedagógica.

O segundo encontro o curso teve início com a leitura e análise das postagens realizadas por um dos participantes. O formador iniciou a leitura com a projeção do post e os participantes acompanharam. No encontro 2, o tema de estudo foi a análise de postagem do Facebook, seguindo o mesmo modelo de estudo em que os professores trocaram impressões de suas leituras. 
No terceiro encontro, foi estudada a ferramenta Canva e a produção dos memes ${ }^{2}$ que circulam na internet. Os trabalhos foram organizados em pequenos grupos. Os professores discutiram entre si e realizaram a atividade proposta pelo formador, a seguir foi realizada a apresentação da produção de cada grupo, cada um com um interlocutor. Não houve discussão ou demandas apresentadas pelo grupão. Feito isso, foi encerrado o encontro.

O quarto e quinto encontro sofreram uma adaptação, como informado pelo formador, para atender à necessidade do grupo. A ideia foi trabalhar uma proposta de ação para o uso do blog na educação, tendo sido suprimida a atividade com Podcast. Formados os pequenos grupos de discussão, foi disponibilizado um tempo de 30 minutos. Os professores se reuniram e iniciaram os trabalhos. As ações propostas, nesse encontro formativo, contaram com a participação dos envolvidos nas discussões em diálogo, na realização dos posts do blog, nos comentários e no planejamento da atividade. Nessa atividade, o formador interferiu pouco nos relatos, não realizou uma reflexão sobre a prática com os professores.

No sexto e último encontro do curso, os professores se basearam na discussão em grupo realizada no encontro anterior e reapresentam suas ideias seguindo do modelo do Roteiro de Atividade Educomunicativo. Foi disponibilizado um link do formulário Google e os participantes realizaram uma avaliação do curso. Em seguida, foi aberta a palavra aos participantes para socializarem suas impressões sobre o curso. Os professores já haviam colocado os apontamentos na plataforma digital e não acrescentaram mais nenhuma sugestão ou opinião sobre a formação. 0 formador foi, então, fechando o encontro, deixando uma proposta aberta ao grupo e à escola para uma possível visita técnica para suporte com o trabalho nos projetos elaborados e discutidos ao longo do curso.

Com o objetivo de avaliar se o processo formativo contribuiu para os professores atuarem, foi criado um grupo de discussão com os professores que participaram da formação como instrumento para coleta de dados e escolhido pelo "aspecto interativo de coleta de dados" (Weller, 2006, p. 243). Isso permitiu a exploração de opiniões coletivas e não somente de opiniões individuais, que expressaram uma série de vivências ou de experiências ligadas à estrutura da escola participante.

Professor C: Você conseguir parar para postar no blog com certa frequência, postar nas redes sociais com uma frequência ainda maior, que tem que ser. A frequência das redes sociais tem que ser. Esse é o desafio complicado da gente conseguir superar. Uma coisa é uma empresa que tem um cara lá só para isso.

Professor T: Mas eu acho que só o fato de que... o blog permite que você inclua diversos autores juntos...Só do fato de várias pessoas poderem acessar. Porque se você centraliza é mais complicado né? Vamos todo mundo mandar para a Sandra (pesquisadora) que a Sandra posta, não adianta, não rola.).

Professor A: E se a gente tentasse alguma coisa na JEIF do ano que vem, que a gente pudesse discutir alguma coisa sobre isso, pudesse trazer alguém que... Porque eu senti falta... Talvez para quem já mexe está muito claro as coisas né? Mas para quem não mexe, quem não tem o blog, por exemplo, quem não acessou o blog, a gente não teve esse tempo, o tempo é pouco.

Na continuidade do grupo de discussão, os professores se debruçam na busca pela solução de um problema real.

\footnotetext{
2 Termo grego que significa imitação, nas redes sociais a ideia de meme pode ser considerada como uma imagem caricata de uma personalidade pública ou um acontecimento recente e que ganha grande repercussão em um curto período de tempo.
} 
Após breve relato dos dois momentos formativos, na escola privada e na escola pública, avançamos para a discussão dos dados apoiados pelas etapas reflexivas do informar, confrontar e reconstruir.

\section{A FORMAÇÃO CONTÍNUA NOS CONTEXTOS PÚBLICO E PRIVADO E O PAPEL DO GESTOR}

Para iniciar a discussão sobre os processos formativos descritos retomamos os objetivos desse trabalho, que é compreender a importância do papel do gestor-formador na formação contínua de professores e coordenadores pedagógicos. Fullan \& Hargreaves $(2000 ; 2001)$ assinalam que para que a formação se constitua na colaboração, é importante a ação conjunta dos agentes envolvidos na construção de um espaço que propicie a participação. Para tal, torna-se essencial que cada um possa acreditar que suas contribuições serão consideradas.

Vemos que no contexto da escola privada o trabalho das coordenadoras pedagógicas acontece em algumas ocasiões sem planejamento, em uma relação confortável. Isso não favorece uma prática voltada a evolução e estudo constante. E, acreditando na formação crítica e colaborativa, é necessário avançar da colaboração confortável para a colaboração crítica (Fullan \& Hargreaves, 2001). Observando as intervenções propostas, verificamos que o trabalho das coordenadoras pedagógicas está focado na esfera do acompanhar e que os processos acontecem, em algumas ocasiões, sem planejamento, em uma relação confortável, o que não favorece uma prática voltada a evolução e estudo constante.

Ainda sobre o contexto da escola privada após a escolha dos encontros e as temáticas, ao classificar as atividades, entendemos que é necessário proporcionar condições para que haja uma formação contínua que realmente promova o desenvolvimento dos sujeitos, e, para isso, uma mudança na configuração do processo é necessária. Nessa reorganização, o compartilhamento das decisões com a equipe de coordenadoras precisa efetivamente favorecer espaços de participação e a formação em momentos individuais e coletivos para formação da equipe e desenvolvimento profissional.

Já, no contexto da escola pública, em que a pesquisadora atuava como gestora, percebemos que os encontros formativos ocorreram com pouca participação dos sujeitos nas decisões. Os professores trocaram impressões sem aprofundamento reflexivo dos valores veiculados em seus relatos. Pode ser percebida a colaboração confortável, em que as ideias e valores não são confrontados para a construção de novas possibilidades.

Entendemos que os encontros formativos devem estar permeados pelo diálogo, pelo agir coletivo e colaborativo na construção do sujeito autônomo e crítico e, sob esse aspecto, o papel do gestor é importante na construção de espaço que permita a colaboração. Identificamos, no contexto de formação da escola pública, o processo de colaboração crítica no grupo de discussão, onde o surgimento de ideias novas pode ser verificado na apresentação de propostas pela participação ativa dos sujeitos. Nesse momento os professores se debruçam na busca pela solução de um problema real, como verificado nos excertos do grupo de discussão em que várias vozes vão construindo o planejamento de uma ação.

Verificamos que o gestor, tanto no contexto da escola pública, como da escola privada, necessita estar aberto à presença da confrontação de ideias, a refutação ou negociação. Esse movimento no encontro marca a presença da colaboração crítica (Liberali, 2015). Retomando Magalhães (2012), pensar a pesquisa desenvolvida numa perspectiva colaborativa é pensá-la como um processo de intervenção formativa, voltada à produção do conhecimento de modo a interferir na realidade, modificá-la. Trata-se de um processo pelo qual as pessoas se tornam sujeitos históricos mediados pelo movimento dialético.

Ficou demonstrado que na unidade particular a falta de planejamento de ações de estudo e, na escola pública, a necessidade de os docentes se reunirem e discutirem situações de problemas 
reais da escola evidencia para os gestores das duas unidades, a necessidade criar e possibilitar momentos de formação, discussão e decisões de suas equipes. Fica claro, então, que a direção e a coordenação, sujeitos dessas pesquisas, necessitam levantar as necessidades buscando o desenvolvimento, vinculando o trabalho na perspectiva crítico-colaborativa entre pesquisadoradiretora, diretoras de unidade e coordenadoras pedagógicas, além de toda a equipe educacional.

Identificamos que no contexto da escola privada que a formação para elas está ligada à ideia de realizar cursos fora da escola e suas ações estão voltadas para uma demanda imediata. Já, no contexto da escola pública, os professores participam da formação sem aprofundamento das discussões sobre a realidade e no grupo de discussão refletem e discutem um problema da escola. Portanto, o papel do gestor na criação de espaços de diálogo e de reflexão sobre a prática em lócus no ambiente escolar são de suma importância para o desenvolvimento da formação crítica colaborativa.

Ao se propor uma formação, deseja-se que as coordenadoras pedagógicas, em parceria, produzam um significado compartilhado sobre as atividades de estudar, formar e acompanhar, com criação de ambientes de formação, para que os sujeitos se percebam como participantes do processo coletivo de transformação.

Conferimos que, conforme Fullan \& Hargreaves (2001), a chave para a renovação está na cultura da cooperação, no comprometimento e responsabilidade partilhados, fortalecendo espaço de maior satisfação e produtividades, onde as pessoas não se veem consumidas pelo grupo, mas enriquecidas por ele. Assim, apontamos que o gestor necessita promover o trabalho na perspectiva crítica colaborativa, a fim de consolidar e promover espaços e temas para reflexão, desenvolvendo a capacidade de trabalhar em equipe.

\section{CONSIDERAÇÕES FINAIS}

Pensando na formação a partir da abordagem TASHC, fica evidenciado o processo de participação dos sujeitos. As pesquisas possibilitaram aos sujeitos participantes, incluindo as pesquisadoras/gestoras, uma reflexão dos contextos de sua atuação e da constituição de um grupo colaborativo, contribuindo, assim, para a construção de um significado compartilhado sobre a atividade em foco (Magalhães, 2012).

Foi possível observar, como colocado por Fullan \& Hargreaves (2000; 2001), que a construção do processo colaborativo pode ter início nesse momento, com os professores agindo coletivamente e planejando ações colaborativas. Para a construção de uma cultura críticocolaborativa com foco e com profundidade, é preciso priorizar o planejamento conjunto, dentro de um tempo que seja necessário para sua constituição. Nessa instância, a participação da gestão escolar é fundamental para a consolidação desse processo.

Sendo assim, considerando as análises realizadas neste trabalho, retomando o caminho metodológico proposto e pretendendo uma reflexão sobre os encontros formativos, evidenciamos alguns apontamentos para reconstrução da formação e atuação do gestor no processo crítico colaborativo: criar espaços com oportunidades para os participantes da formação confrontarem suas ideias (Liberali, 2015; Fullan \& Hargreaves 2001; Magalhães, 2012); provocar a reflexão crítica e mostrar-se preparado para a escuta e para a mudança (Liberali, 2015); possibilitar condições aos docentes e coordenadores pedagógicos construírem sua própria produção permeados pelo diálogo; e criar situações em que o sujeito tenha que analisar, prever e redesenhar suas atividades (Liberali, 2015).

Buscamos refletir nos contextos da formação contínua de professores na escola pública e da formação de coordenadores pedagógicos na escola privada, no entanto, não pretendemos encerrar as discussões, pois entendemos que muitos fatores são importantes na construção de um processo de formação contínua. Neste trabalho, buscamos refletir os contextos e apontar caminhos que 
permitam transformações e promoção do desenvolvimento crítico colaborativo de todos os envolvidos: pesquisadores, professores, coordenadores pedagógicos e alunos.

Contribuições dos Autores: Santella Sousa, S.: concepção e desenho, aquisição de dados, análise e interpretação dos dados, redação do artigo, revisão crítica relevante do conteúdo intelectual; Liberali, F. C.: concepção e desenho, aquisição de dados, análise e interpretação dos dados, redação do artigo, revisão crítica relevante do conteúdo intelectual; David Silva, C. R. P.: concepção e desenho, aquisição de dados, análise e interpretação dos dados, redação do artigo, revisão crítica relevante do conteúdo intelectual. Todas as autoras leram e aprovaram a versão final do manuscrito.

Aprovação Ética: Aprovado pelo Comitê de Ética em Pesquisa em Seres Humanos da Pontifícia Universidade Católica de São Paulo. Number: 3.261.055 and 3.332.883.

Agradecimentos: Não aplicável.

\section{REFERÊNCIAS}

Almeida, L. R., \& Placco, V. M. N. (2012). O Coordenador pedagógico e Questões de Contemporaneidade. São Paulo: Edições Loyola.

Almeida, L. R., \& Placco, V. M. N. S. (2009). O papel do Coordenador Pedagógico. Revista Educação. Ed. Segmento, 12(142), 38-39.

David Silva, C. R. P. (2019). A dimensão formativa do diretor escolar: análise de um processo crítico-colaborativo em Cadeia Criativa. Dissertação. Pontifícia Universidade Católica de São Paulo. São Paulo.

Fullan, M. (2001). Por que é que vale a pena lutar? O trabalho de equipe na escola. Porto Editora.

Fullan, M., \& Hargreaves, A. (2000). A escola como organização aprendente: buscando uma educação de qualidade. Porto Alegre: Artmed.

Imbernón, F. (2011). Formação Docente e Profissional. São Paulo: Cortez.

La Luna (2019). Direção: Enrico Casarosa. Disney Pixar. Estados Unidos: Disney Pixar. Disponível em: https://www.youtube.com/watch?v=Pe7Uip-tX9Q

Liberali, F. (2009) Formação de professores e pesquisadores: Argumentando e compartilhando significados. In: Telles, J. A. (Org.). Formação inicial e continuada de professores de língua Dimensões e ações na pesquisa e na prática. Campinas: Pontes Editores, 43-66.

Liberali, F. (2015). Formação crítica de educadores: Questões fundamentais. Campinas, SP: Pontes Editores.

Liberali, F. (2017). Entrelaces Vygotskyanos. Caderno de Resumos. ISCAR Brasil: Londrina.

Liberali, F. C. (2013). Argumentação em contexto escolar. Campinas: Pontes Editores.

Liberali, F. C., \& Magalhães, M. C. C. (2004). O Interacionismo Sociodiscursivo em pesquisas com formação de educadores. Calidoscópio, 2(2), 105-112.

Magalhães, M. C. C. (2004). As Linguagens das reflexões. In. Magalhães, M. C. C. (org.). A linguagem na formação de professores como profissionais reflexivos críticos. São Paulo: Mercado das Letras, 87-117.

Magalhães, M. C. C. (2012). Vygotsky e a pesquisa de intervenção no contexto escolar: pesquisa crítica de colaboração: PCCol. Alfa, 61(3), 625-652.

Magalhães, M. C. C., \& Ninin, M. O. G. (2017). A Linguagem da Colaboração Crítica no desenvolvimento da agência de professores de Ensino Médio em serviço. Alfa, 61(3), 625-652.

Nóvoa, A. (1995). Profissão Professor. Porto, Portugal: Porto Editora.

Placco, V. M. N. S., \& Souza, V. L. T. (2010). Diferentes Aprendizagens do Coordenador Pedagógico. In: Almeida, L. R., \& Placco, V. M. N. S. (Org.) O Coordenador Pedagógico e o atendimento à diversidade. São Paulo: Edições Loyola, 4761.

Santella Sousa, S. (2019). A educomunicação e a formação de professores: o papel do programa Imprensa Jovem na construção da formação crítico colaborativa. Dissertação. Pontifícia Universidade Católica de São Paulo. São Paulo.

Smyth, J. (1992) Teachers work and the politics of reflection. América educational Reserach journal, 29(2), 267-300. 
Vygotsky, L. S. (1999). Pensamento e linguagem. São Paulo: Martins Fontes.

Vygotsky, L. S. (2000). A construção do pensamento e da linguagem. São Paulo: Martins Fontes.

Vygotsky, L. S. (2007). A formação social da mente. 7ạ ed. São Paulo: Martins Fontes.

Weller, W. (2006). Grupos de discussão na pesquisa com adolescentes e jovens: aportes teórico-metodológicos e análise de uma experiência com o método. Educação e Pesquisa, 32(2), 241-260.

Recebido: 8 de agosto de 2020 | Aceito: 2 de julho de 2021 | Publicado: 19 de agosto de 2021

This is an Open Access article distributed under the terms of the Creative Commons Attribution License, which permits unrestricted use, distribution, and reproduction in any medium, provided the original work is properly cited. 